\title{
GNOJIDBA PŠENICE U SUSTAVU PRECIZNE POLJOPRIVREDE
}

\author{
WHEAT FERTILIZATION IN A PRECISION FARMING SYSTEM
}

\author{
Irena Rapčan, M. Jurišić, I. Plaščak, Ž. Barač, D. Zimmer, M. Bognar
}

\section{SAŽETAK}

Primjena precizne poljoprivrede podrazumijeva uštedu vremena, mineralnih gnojiva, financijskih sredstava, a povećava prinos i kakvoću uroda. U radu je opisana raspodjela mineralnih gnojiva u usjevu pšenice u sustavu precizne poljoprivrede na poljoprivrednom gospodarstvu u vlasništvu Marijana Bognara iz Crnca, Virovitičko-podravska županija. Gnojidbu je obavila tvrtka PP Orahovica, a korišten je vučeni rasipač Amazon ZG-Drive s automatskim sustavom gnojidbe preko Amatron+ sustava, integriranog sustava s navigacijskom tehnologijom (GIS) i kontrolom rada rasipača.

Ključne riječi: GIS, precizna poljoprivreda, gnojidba, pšenica, prinos

\section{ABSTRACT}

The application of precision agriculture ultimately means saving time, mineral fertilizers and financial resources, and increasing yield and yield quality. The distribution of mineral fertilizers in wheat crop in the system of precision agriculture on Marijan Bognar's agricultural economy from Crnac, Virovitica - Podravina Canton is described in this paper. The fertilization was performed by the PP Orahovica company, and the Amazon ZG-Drive traction sheave was used with the automatic fertilizer system through the Amatron + system, an integrated system with navigation technology and spread control.

Key words: GIS, precision agriculture, fertilization, wheat, yield

\section{UVOD}

Korištenjem GIS sustava optimiziraju se inputi i definiraju outputi za zadovoljavanje potrošača u realnom vremenu. GIS tehnologija pomaže kod ujedinjavanja podataka za analizu i planiranje proizvodnje, kao i kartografski pregled i informativna izvješća o zemljištu i uzgajanoj kulturi. Postupci 
lokacijsko orijentiranog menadžmenta (site specific management - SSM) predloženi kao dio sustava precizne poljoprivrede pružaju poljoprivredniku mogućnost povećanja prinosa, smanjenje inputa i smanjenje utjecaja na okoliš na najmanju moguću mjeru (Robert, 2002.; Robertson i sur., 2012.; Basso i sur., 2013.). Osnovni cilj precizne poljoprivrede je povećati broj preciznih informacija u realnom vremenu kako bi bile na raspolaganju poljoprivredniku prilikom donošenja odluka. Izravna usporedba višegodišnjih parametara dobivenih s parcela rezultira sve svrsishodnijom, argumentiranom i optimalnom upotrebom sredstava za rad, smanjenjem nepovoljnih utjecaja na okoliš te povećanjem količine i kakvoće proizvoda. Naime, poljoprivreda se treba podjednako ravnati i po ekonomskim i po ekološkim zahtjevima, a neke od njih navode Jurišić i Plaščak (2009.): učinkovita upotreba sirovina (gnojiva, sredstava za zaštitu bilja, stočna hrana); smanjenje štetnog opterećenja ekosustava (primjerice nitrati, pesticidi...); prikladan uzgoj životinja; stvaranje ciklusa recikliranja (prirodni plin i kompostiranje); proizvodnja obnovljivih nositelja energije (sadnja energetskih biljaka, biološka goriva) te briga o krajoliku.

\section{MATERIJAL I METODE}

Istraživanja su obavljena na površini od 1 ha u vlasništvu PG Marijan Bognar u Crncu $\left(45^{\circ} 41^{\prime} \mathrm{N}, 17^{\circ} 56^{\prime} \mathrm{E}, 96 \mathrm{~m}\right.$ nadmorske visine), Virovitičkopodravska županija. Predusjev na površini je bila šećerna repa, a uzgajan usjev jara pšenica s planiranim prinosom od 6 t/ha. Neophodno je prethodno prikupiti potrebne podatke o određenoj parceli. To uključuje izradu karte konduktiviteta tla, uzorkovanje tla, analizu tla i preporuku za gnojidbu te izradu karata raspodjele hraniva. Po prikupljenim podacima moguće je obaviti preciznu gnojidbu. Elektromagnetsko mapiranje mjeri poroznost/teksturu tla, pa tako tla s visokom poroznošću imaju veći električni konduktivitet. Tla s visokim sadržajem gline prikazat će se kao područja s većim vrijednostima električnog konduktiviteta, što je povezano sa sadržajem vode u tlu. Uzorkovanje se temelji na poljskim varijacijama, topografiji parcele i tipu tla. Uzorci se uzimaju do dubine od $30 \mathrm{~cm}$, a prosječan uzorak činio je 25 uboda sondom odnosno $1-2 \mathrm{~kg}$ tla (Ryšan i Šarec, 2008.). Analizom tla utvrđuju se sadržaj hraniva u tlu (fosfora i kalija), identificira manjak ili višak pojedinog hraniva, procjenjuje reakcija usjeva na dodana hraniva, temelji plan gnojidbe i procjenjuje trenutna plodnost. Na temelju tih vrijednosti daje se preporuka za gnojidbu usjeva. Pomoću SMS softwarea izrađene su karte raspodjele hraniva na temelju kojih se provodi gnojidba. 
Kontaktni senzori za mjerenje električnog konduktiviteta sastoje se od dva do tri para elektroda-crtala koja ulaze u tlo nekoliko centimetara. Jedan par elektroda (odašiljač) provodi električnu struju u tlo, dok ostali parovi (prijamnici) mjere pad napona među njima te na taj način izračunavaju električni konduktivitet tla te se rezultati prikazuju na karti (Slika 1.). Uzorkovanje tla provedeno je na cijeloj parceli prema sustavu mreže, kako je prikazano na Slici 2.
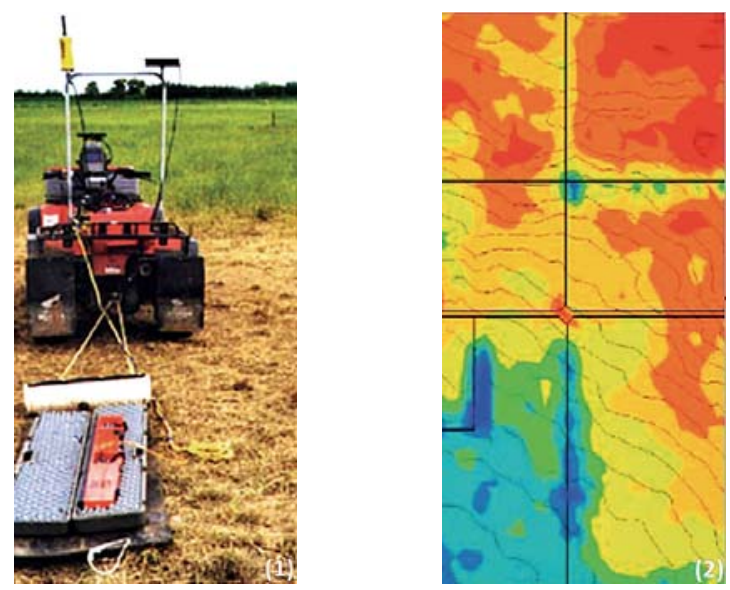

Slika 1. Elektro-magnetsko mapiranje (1) i karta električnog konduktiviteta tla (2)

Figure 1 Electro-magnetic mapping (1) and map of electrical conductivity of the soil (2)

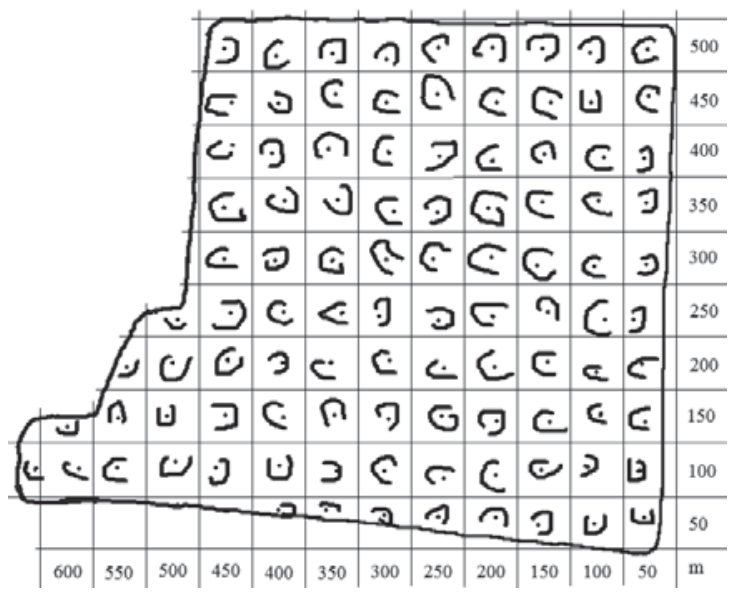

Slika 2. Mjesta uzorkovanja tla na parceli

Figure 2 Soil sampling sites on the plot 


\section{REZULTATI I RASPRAVA}

Nakon izvršene analize uzoraka tla laboratorij izdaje preporuku za gnojidbu. Pomoću SMS softwarea izrađene su karte raspodjele fosfora (Slika 3.) i kalija (Slika 4.). Prema preporuci za gnojidbu u predsjetvenoj gnojidbi primijenjeno je $100 \mathrm{~kg} / \mathrm{ha}$ kalijeve soli $(40 \% \mathrm{~K}) \mathrm{u}$ granuliranom obliku, $100 \mathrm{~kg} / \mathrm{ha}$ NPK gnojiva 7-20-30 i 15-15-15 te $50 \mathrm{~kg} / \mathrm{ha}$ uree (46\% N). Gnojidba je obavljena s rasipačem gnojiva Amazon Drive (Slika 5.) spremnika 5.500 1, prema unaprijed izrađenim kartama raspodjele gnojiva. Korišten je sustav Amatron $+\mathrm{u}$ koji su podatci o karti raspodjele hraniva i preciznoj raspodjeli preneseni iz stolnog računala putem memorijske kartice. Amatron + kontrolira rad rasipača tako da otvara zasun na otvoru iznad diskova i brzinu trake za transport gnojiva do zasuna prema unaprijed utvrđenim potrebama za raspodjelom. Upravljanje traktorom obavljeno je GPS tehnologijom koja točno određuje poziciju traktora i šalje sve potrebne informacije sustavu Amatron + koji pohranjuje podatke u memoriju.

$\mathrm{S}$ tim informacijama koje se potom prebacuju u stolno računalo olakšava se planiranje poljoprivredne proizvodnje. Amatron + sustav automatskog upravljanja radom rasipača olakšava primjenu, jer prilikom primjene nije potrebno održavati stalnu brzinu traktora. Sustav registrira sve mehaničke prepreke koje se nalaze na putu te pohranjuje te informacije u memoriju.

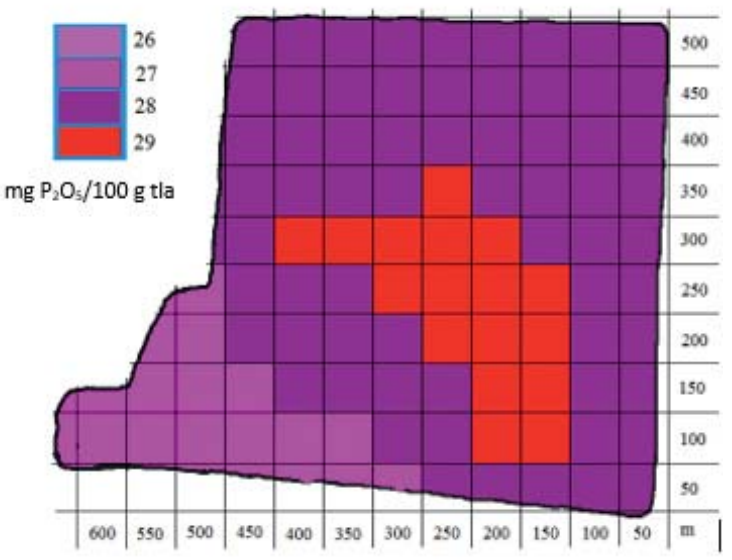

Slika 3. Karta raspodjele fosfora na parceli

Figure 3 The map of phosphorus distribution on the plot

Prilikom prolaska po granici parcela sustav automatskom kontrolom limiter sustava ograničava širinu zahvata rasipača te ujednačuje količinu raspodijeljenog gnojiva uz rub parcele. Prilikom raspodjele gnojiva širina zahvata rasipača je podešena na $24 \mathrm{~m}$ da se smanji broj prohoda s rasipačem i uštedi na gorivu. 
Irena Rapčan i sur.: Gnojidba pšenice u sustavu precizne poljoprivrede

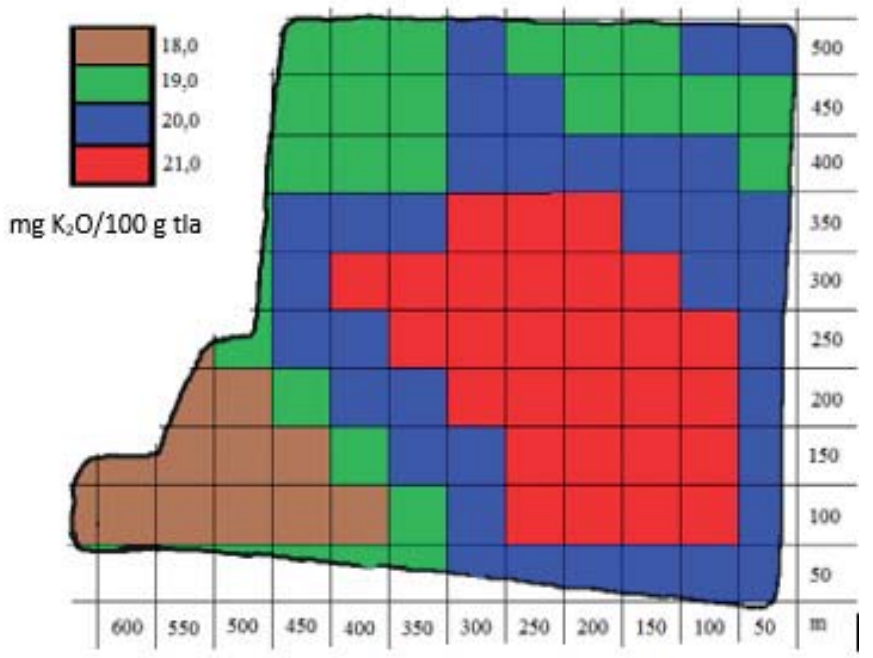

Slika 4. Karta raspodjele kalija na parceli

Figure 4 Map of distribution of potassium on a plot

U proljeće je u prvoj prihrani primijenjen KAN (27\%) u dozi od $150 \mathrm{~kg} / \mathrm{ha}$, dok su druga i treća prihrana obavljena u dozi od $100 \mathrm{~kg} / \mathrm{ha}$ istog gnojiva. Širina zahvata rasipača podešena je na $18 \mathrm{~m}$ radi upotrebe istih tragova prohoda prilikom prskanja i prilikom apliciranja gnojiva. Podešavanje diskova za raspodjelu gnojiva je kod Amazona prilično jednostavno bez upotrebe alata, a obavlja se na samom disku postavljanjem konusa lopatica na predviđenu poziciju koja je obilježena na disku. Također je smanjena i dužina lopatica te njihov kut na završnom dijelu koji je također zabilježen na disku. Maksimalnu točnost mjerenja osigurava opcionalni integrirani sustav za vaganje gnojiva, kontroliranom raspodjelom. Odstupanje u raspodjeli mineralnih gnojiva odmah je vidljiva, isto tako je odmah vidljiva i širina zahvata. Zadanu količinu gnojiva sustav automatski podešava prema zadanoj karti raspodjele mineralnih gnojiva, neovisno o promjeru granula gnojiva. Povećana fleksibilnost raspodjele mineralnih gnojiva osigurava hidraulički pogon sustava raspodjele koji automatski, neovisno o broju okretaja kardanskog vratila, fleksibilno pogoni pogon diskova za raspodjelu gnojiva i održava optimalnu kutnu brzinu diskova. Fleksibilni pogonski sustav smanjuje napor stroja i rukovatelja te štedi gorivo, jer je moguće raditi s rasipačem i pri nižem režimu okretaja motora održavajući i optimalan broj okretaja motora. 


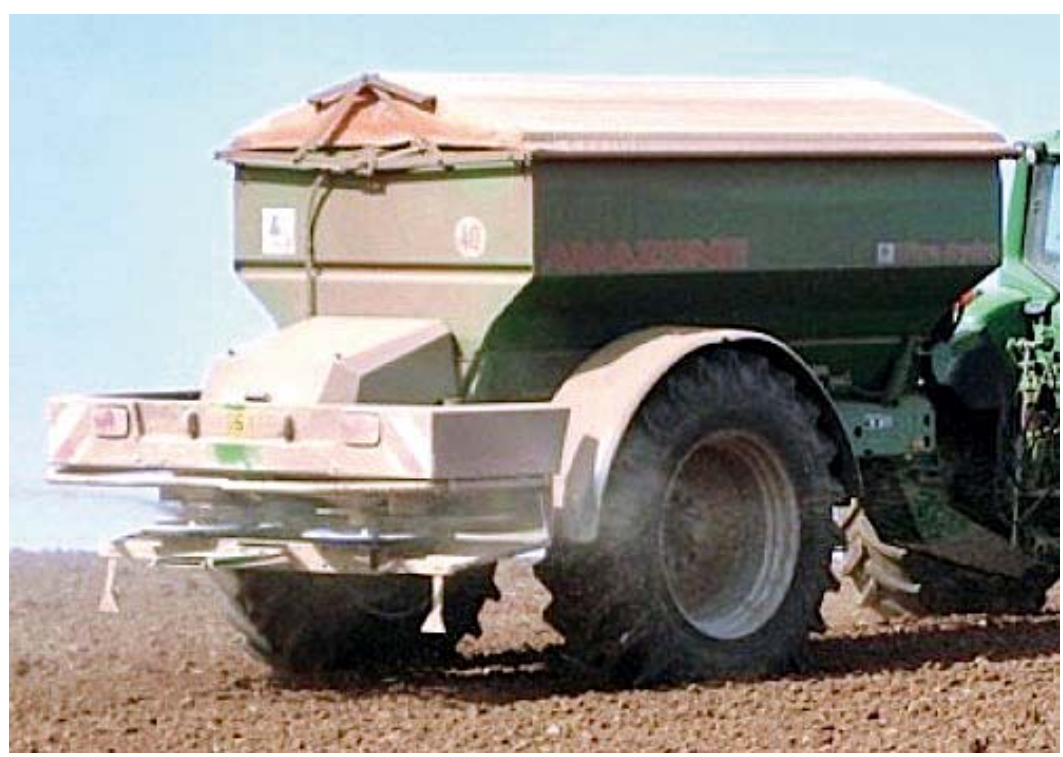

Slika 5. Rasipač Amazon Drive u radu

Figure 5 Amazon Drive dispenser in operation

Uz pomoć OptRx senzora (Slika 6.) može se raspodijeliti dušik na poljoprivrednu površinu preciznije nego je to rađeno do sada. Senzor radi u dijelu spektra vrlo blizu infracrvenom, a postavlja se ili na traktor ili na priključni stroj kojim se vrši raspodjela gnojiva ili zaštitnog sredstva i cijelo vrijeme tijekom kretanja traktora snima se poljoprivredna kultura. Senzor od biljke prima reflektirani dio svjetla i na taj način detektira VI (vegetativni indeks). Na taj način senzor čita vrijednosti u polju i uspoređuje ih $s$ referentnom vrijednošću na ostatku polja. Ovisno o intenzitetu boje biljke direktno komunicira s upravljačkom jedinicom raspodjeljivača gnojiva i tako mijenja dozu. Na taj način će određene zone polja dobiti veću, a druge manju količinu gnojiva pri čemu je cilj ujednačenost kvalitete kulture na polju. OptRx baca svjetlost na vrh usjeva i senzorom očitava reflektiranu svjetlost; preko ugrađenog software-a i kalibracije senzora, OptRx koristi očitanja senzora kako bi odredio energiju usjeva (VI). Na osnovi VI očitanja OptRx varira i određuje razinu dušika za ostvarenje maksimalnog uroda. Kako bi se odredila referentna vrijednost vegetativnog indeksa (VI), traktor sa senzorima mora se voziti preko najzdravijih biljaka minimalno 5 minuta. Time se kalibrira OptRx senzor za trenutnu fazu rasta. 


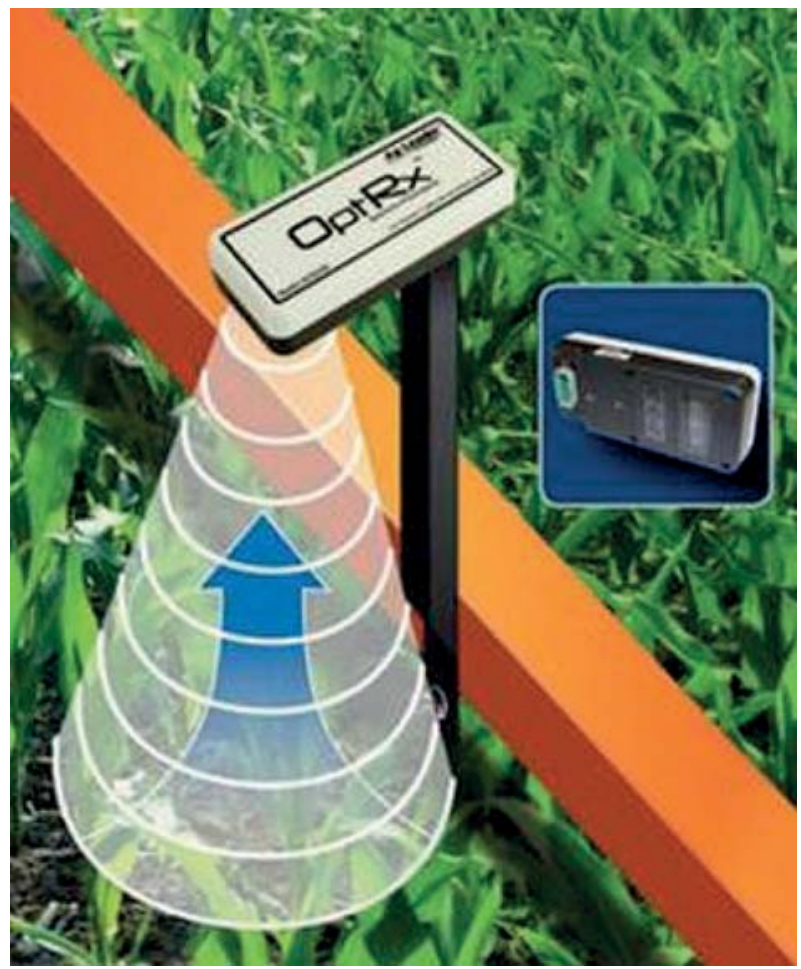

Slika 6. OptRx senzor

Figure 6 OptRx sensor

(izvor: http://www.savjetodavna.hr/vijesti/8/3192)

\section{ZAKLJUČAK}

Precizna poljoprivreda je sustav upravljanja u bilinogojstvu gdje se uz primjenu novih tehnologija prikupljaju podaci, obrađuju i primjenjuju na poljoprivrednoj površini. Pri prikupljanju podataka koriste se različiti senzori koji uz GPS određuju lokaciju stroja i bilježe podatke na uređaj. Obavlja se prikupljanje podataka uzorkovanjem, mjeri se elektrokonduktivitet, zapis gnojidbe, kartira se prinos i slično. Gnojidba je jedan od važnijih čimbenika u poljoprivrednoj proizvodnji kojim se osiguravaju stabilniji prinosi i smanjuju nepotrebni troškovi. Vegetacija upija crvenu i plavu svjetlost, a zrcali zelenu te biljke izgledaju zeleno, upravo zbog toga NDVI senzori koriste crvenu i blisko 
Irena Rapčan i sur.: Gnojidba pšenice u sustavu precizne poljoprivrede

crvenu svjetlost (NIR). Reflektirana svjetlost se bilježi i pomoću formule određuje vegetacijski indeks, pomoću kojeg se određuje raspodjela gnojiva za kulturu. Ag Leader OptRx senzori odašilju vlastiti izvor svjetla, a izlazni parametar senzora temelji se na biljnoj masi usjeva i reflektiranoj svjetlosti. Vegetacijski indeks (VI) se izračunava u realnom vremenu, a na temelju očitanja usjeva. Pomoću vegetacijskog indeksa senzor izravno očitava vrijednosti dušika po promjenjivim stopama i stvara virtualnu bazu podataka u realnom vremenu, a u odnosu na referentnu odnosno zadanu vrijednost.

\section{LITERATURA}

1. Basso, B., Cammarano, D., Fiorentino, D., Ritchie, J. T. (2013.): Wheat yield response to spatially variable nitrogen fertilizer in Mediterranean environment. European Journal of Agronomy 51: 65 - 70.

2. Bognar, M. (2013.): Tehnološko-tehnički činitelji gnojidbe u sustavu precizne poljoprivrede. Diplomski rad. Poljoprivredni fakultet u Osijeku, Osijek.

3. Jurišić M., Plaščak I. (2009.): Geoinformacijski sustavi. GIS u poljoprivredi i zaštiti okoliša. Poljoprivredni fakultet u Osijeku. Osijek.

4. Koch B. Khosla R. (2003.): The Role of Precision Agriculture in Cropping Systems. Colorado State University. Fort Collins, CO., USA.

5. Precision agriculture. (2012.): New Holland. Factory instructions.

6. Precision Fertilization. (2011.): Amazone ZG-B. Factory instructions.

7. Robert, P.C. (2002.): Precision agriculture: a challenge for crop nutritionmanagement. Plant soil, 247(1): 143 - 149.

8. Robertson, M. J., Llewellyn, R. S., Mandel, R., Lawes, R., Bramley, R. G. V., Swift, L., Metz, N., O'Callaghan, C. (2012.): Adoption of variable rate fertiliser application in the Australian grains industry: status, issues and prospects. Precision Agriculture 13(2): 181-199.

9. Ryšan, L., Šarec, O. (2008): Research of correlation between electric soil conductivity and yield based on the use of GPS technology. Research in agricultural engineering 54 (3): $136-147$.

10. http://ebookbrowse.com/santic-marko-diplomski-pdf-d28918375. (6.12.2017.).

11. http://ishranabilja.com.hr/Analiza_tla/analiza_tla.htm. (7.12.2017.).

12. http://www.savjetodavna.hr/vijesti/8/3192/precizna-raspodjela-dusika-pomocusenzora/ (1.12.2017.)

13. http://www.dgu.hr/. (1.12.2017.).

14. http://www.geofoto.hr/. (1.12.2017.). 
Adrese autora - Author's addresses:

Primljeno - Received:

Izv. prof. dr. sc. Irena Rapčan,

30.06.2018.

Prof. dr. sc. Mladen Jurišić,

Doc. dr. sc. Ivan Plaščak,

Željko Barač, mag. ing. agr., e-mail: zbarac@pfos.hr

Domagoj Zimmer, mag. ing. agr.

Fakultet agrobiotehničkih znanosti, Vladimira Preloga 1,

31000 Osijek, Hrvatska

Marijan Bognar, mag. ing. agr,

Obiteljsko poljoprivredno gospodarstvo (OPG) Marijan Bognar,

33507 Crnac, Hrvatska 
